\title{
Editorial
}

\section{Special issue: Pellat thesis prize winners}

\author{
T. Gibert ${ }^{1}$ and T. Passot $^{2} \uparrow$ \\ ${ }^{1}$ GREMI, 14 rue d'Issoudun, 45067 Orléans CEDEX 2, France \\ ${ }^{2}$ Université Côte d'Azur, CNRS, Observatoire de la Côte d'Azur, Boulevard de l'Observatoire, \\ CS 34229, 06304 Nice CEDEX 4, France
}

(Received 30 June 2016; revised 1 July 2016; accepted 4 July 2016)

The René Pellat Prize is a distinction awarded every year by the French Physical Society (SFP) to a young doctor of a French laboratory. The prize rewards remarkable work in the field of plasma physics.

René Pellat (1936-2003) is a great figure of plasma physics. He was first engineer at the Commissariat à l'Énergie Atomique (CEA), then became researcher at CNRS and won the CNRS silver medal in 1972 for his work on controlled nuclear fusion, before working on stellar physics and astrophysics. Alongside his research activities, which he continued throughout his life (as attested to by his 300 publications), he occupied high level positions: president of CNRS (1989-1992), of CNES (1992-1995), of the ONERA scientific council (1996-2003), Haut commissaire (Head) of CEA (1997-2003), delegate to the nuclear safety and to the radioprotection for defence installations and activities. Fierce defender of the ITER international project, he strongly contributed to its implantation on the French site of Cadarache. He was also a visiting professor at the University of California, Los Angeles (UCLA) from 1987 to 2003 .

The Pellat prize jury is composed of members of the SFP plasma division. Three main plasma physics communities are represented: cold or industrial plasmas, hot plasmas and natural plasmas. The jury rewards a significant breakthrough in one of these fields, whether theoretical, experimental, fundamental or applied. The René Pellat prize is awarded either during the plasma congress (on pair years) or at the general SFP congress. The winner is encouraged to give a talk on his work during the meeting.

Participation in a special issue of the Journal of Plasma Physics dealing with the work of the Pellat Prize laureates is an opportunity to highlight new research directions and to contribute to the scientific influence of young laureates.

\section{Winners of the Pellat thesis prize 2011-2016}

(i) 2011: Sédina Tsikata, Laboratoire de Physique des Plasmas, École Polytechnique. Thesis title: 'Small-scale electron density fluctuations in the Hall thruster, investigated by collective light scattering.'

(ii) 2012: Nicolas Aunai, Laboratoire de Physique des Plasmas, École Polytechnique. Thesis title: 'Simulation numérique de la reconnexion magnétique : mécanismes cinétiques sous-jacents à la description fluide des ions.' 
(iii) 2013: Daniil Marinova, Laboratoire de Physique des Plasmas, École Polytechnique. Thesis title: 'Reactive adsorption of Molecules and Radicals on Surfaces under Plasma Exposure.'

(iv) 2014 Sébastien Corde, Laboratoire d'Optique Appliquée, ENSTA ParisTech, École Polytechnique.

Thesis title: 'Des accélérateurs laser-plasma aux sources de rayonnement X femtoseconde : étude, développement et applications.'

(v) 2015 Stéphane Cuynet, Laboratoire GREMI, Université d'Orléans.

Thesis title: 'Étude des conditions d'élaboration d'électrodes de pile à combustible PEMFC par procédés plasma.'

(vi) 2016 Hugo Arnichand, IRFM, CEA.

Thesis title: 'Identification of trapped electron modes in frequency fluctuation spectra of fusion plasmas'. 